\title{
Urinary tract infections in spinal cord injury patients undergoing intermittent catheterization procedures
}

TERESA KIRKLAND, BSCN, GEOFFREY D TAYLOR, MD

\begin{abstract}
T KIRKLAND, GD TAYLOR. Urinary tract infections in spinal cord injury patients undergoing intermittent catheterization procedures. Can J Infect Dis 1992;3(3):129-133. A prospective study was organized to assess whether feeding back infection rates to staff performing intermittent catheterization in spinal cord-injured patients would produce a fall in urinary tract infection rates. Over a 12 month period, infection rates for such procedures were reported to unit staff; reporting was combined with educational programs emphasizing aseptic catheterization techniques and the importance of handwashing. Overall infection rates for the 12 month period were 13.3 per 1000 days of intermittent catheterization - unchanged from the preceding six months (15.1 per 1000 days) by retrospective chart review. Likewise, there was no statistically significant downward trend during the prospective phase of the study. A wide variety of infecting organisms were found, of which Klebsiella species (39\%), Escherichia coli (18\%) and Enterobacter species (17\%) were most common; most infections were asymptomatic. Patients with complete cord lesions at or above the sixth thoracic spinal cord segment (T6) had a much higher incidence of infection (73\%) than those with incomplete lesions below T6 (33\%).
\end{abstract}

Key Words: Intermittent catheterization, Spinal cord injury, Urinary tract infection

\section{Infections des voies urinaires et cathétérisme périodique en centre de traumatologie spinale}

RESUME: Les auteurs ont effectué une étude prospective. Il s'agissait de déterminer si le fait de communiquer les taux d'infection au personnel effectuant un cathétérisme périodique chez les patients atteints de lésions de la moelle épinière provoquerait une baisse des taux d'infections urinaires. Sur une période de 12 mois, ces données ont donc été rapportées au personnel du centre de traumatologie spinale, qui a également suivi des programmes éducatifs traitant des techniques d'asepsie et soulignant l'importance de se laver les mains. L’analyse rétrospective des dossiers révèle que le taux général d'infection pour cette période était de 13,3 pour 1000 jours de cathétérisme intermittent, ce qui ne représentait pas de changement notable par rapport aux six mois précédents (15,1 pour 1000 jours). On n'a pas non plus noté de tendance significativement à la baisse durant la phase prospective de la présente étude. Une grande variété de micro-organismes ont été décelés; Klebsiella (39\%), Escherichia coli (18\%) et Enterobacter (17\%) étaient les plus communs et la plupart des infections étaient asymptomatiques. Atteignant $73 \%$, les infections étaient beaucoup plus fréquentes chez les patients ayant subi une lésion totale de la moelle au niveau des sixièmes vertèbres dorsales (D6) ou au-dessus. Elles étaient de $33 \%$ dans les cas d'atteintes partielles au-dessous du segment D6. 
I: NTERMITTENT CATHETERIZATION PERFORMED UNDER sterile conditions is a well accepted method of managing acute spinal cord injury patients with a view to reducing the urinary infection rate. Nevertheless, bacteriuria is common and resultant upper tract infections remain an important cause of morbidity in this population. Most attempts to reduce further infection rates have focused on the use of prophylactic urinary antiseptics or antibiotics (1-4). The authors postulated that an important variable in the development of urinary tract infections (UTIs) in this setting is the skill and attention of the individual performing the procedure, and that this could be influenced positively by reporting infection rates on a regular basis to these operators, similar to programs reporting wound infection rates to practising surgeons (5). This report is a study of a program of regular reporting of infection rates to unit staff compared with a retrospectively obtained baseline rate in the same population.

\section{PATIENTS AND METHODS}

The University of Alberta Hospital is a 1355-bed acute tertiary care hospital providing all spinal cord rehabilitation services to northern Alberta. Once stabilized in an acute care setting, spinal cord-injured patients are transferred to the 26-bed rehabilitation unit in the same institution. The patient population on the rehabilitation unit is a mix of amputees and spinal cord-injured patients, the latter making up $80 \%$ of the total population. The facility housing the rehabilitation unit was constructed in the 1950s, and system design has limited the number of sinks that can be installed. A total of 10 sinks are present on the unit: three in the communal male washroom, three in the communal female washroom, two in the 'utility rooms' (clean/ dirty), one in the hallway and one in the patient lounge. In January 1986 the staff of the spinal cord rehabilitation unit contacted the infection control unit with concerns that they were seeing excessive numbers of UTIs. Consequently, the authors studied the problem by retrospective analysis of UTIs in the unit's patients over the preceding six months, and prospective analysis for the subsequent 12 months. Each patient studied had bladder dysfunction requiring more than one intermittent catheterization each 24 h. Catheterization was carried out by a trained group of orderlies (for male patients) or by registered nurses or registered nurse assistants (for female patients), all of whom were permanently assigned to the unit. Patients can perform their own catheterization as part of the training process and follow the same technique while in hospital. Sterile technique, including the use of a chlorhexidine solution for cleansing, was employed in the catheterization procedure (6).

Urine cultures were submitted every two weeks for each patient and if a patient demonstrated clinical signs and/or symptoms suggestive of UTI. This ward practice remained unchanged throughout the retro spective and prospective phases of the study. UTI wa documented if: greater than $10^{6}$ colonies/L were iso lated in a symptomatic patients; greater than 10 colonies/L were isolated on two separate occasions ir an asymptomatic patient; or greater than 10 colonies/L were isolated on one occasion if eithe prophylactic or therapeutic antibiotics were prescribec without first repeating the urine culture (7).

A culture was regarded as representing a relapse i the criteria for UTI were met, but the same bacteria species with identical antibiotic sensitivities was iso lated fewer than 14 days after completion of a course 0 antimicrobial therapy. Typing of isolates was not car ried out to confirm strain identity.

Prophylactic antibiotics were not prescribed under any circumstance. Asymptomatic UTIs were treated when culture results became available with oral agents based on sensitivity data. Patients with clinical signs and symptoms of systemic infection often had therapy initiated (usually ampicillin and gentamicin) pending culture results, with subsequent modification of therapy. Asymptomatic infections were generally treated with five to seven days of therapy, and symptomati infections 10 to 14 days, except in the case of relapses which were usually treated with longer courses.

The retrospective study was carried out by review o the medical records of all spinal cord-injured patients admitted to the same unit over a six month period (August 1985 to January 1986). The prospective study was carried out over a 12 month period from February 1986 to January 1987. One of the authors (TK) visited the unit twice weekly to collect data by examining the medical records. Formal education sessions to review appropriate handwashing technique and aseptic cath eterization procedure with health care workers were conducted on a weekly basis for the first month during the prospective phase of the study. Continuing educa tion occurred informally at the time of surveillance visits. Reports of infection rates were issued monthly to medical and nursing staff, prominently displayed on the unit, and informally discussed with various mem bers of the health care team.

\section{RESULTS}

During the 18 month study period, 69 patients were admitted for a total of 6400 days of intermittent catheterization procedures. Eighty-five infections wer seen in 38 patients. Overall, $55 \%$ of patients experienced at least one UTI. When calculated as infec tions per 1000 days of intermittent catheterization procedures, the infection rate was 13.3: 12.4 in the prospective period and 15.1 in the retrospective period $(\mathrm{P}=0.44)$. Figure 1 gives the infection rate by month for each period. Quarterly infection rates per 1000 days o intermittent catheterization procedures during the prospective period were $14.7,12.5,11.0$ and 11.1 


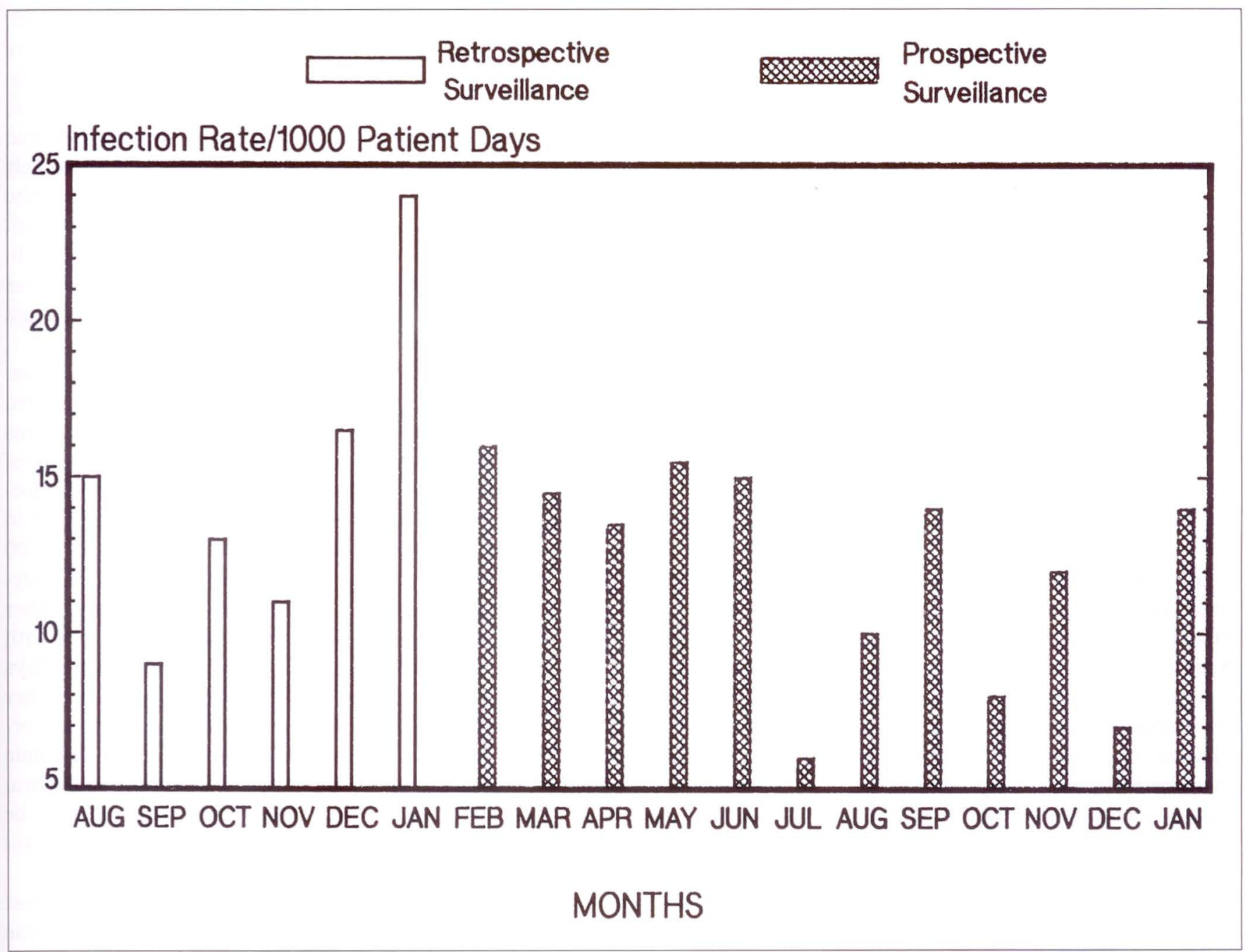

Figure 1) Infection rates per 1000 patient days of intermittent catheterization procedures in 69 spinal cord-injured patients at the University of Alberta Hospitals. Surveillance periods were August 1985 to January 1986 (retrospective) and February 1986 to January 1987 (prospective)

TABLE 1

Infection rate by site and completeness of cord lesion

\begin{tabular}{|c|c|c|c|c|c|c|c|}
\hline \multirow[b]{2}{*}{ T6 or higher, complete } & \multicolumn{2}{|c|}{ Patients (\%) } & \multicolumn{2}{|c|}{$\begin{array}{l}\text { Patients with at least } \\
\text { one infection (\%) }\end{array}$} & \multicolumn{2}{|c|}{$\begin{array}{c}\text { Number of infections } \\
(\%)\end{array}$} & \multirow{2}{*}{$\begin{array}{c}\text { Infection rate per } \\
1000 \text { ICP days } \\
13.6\end{array}$} \\
\hline & 31 & $(45)$ & 22 & $(58)^{*}$ & 57 & $(67)$ & \\
\hline T6 or higher, incomplete & 14 & $(20)$ & 6 & (16) & 16 & (19) & 17.2 \\
\hline Below T6, complete & 13 & (19) & 6 & (16) & 9 & (11) & 11.7 \\
\hline Below T6, incomplete & 12 & $(17)$ & 4 & (12) & 3 & (4) & 6.0 \\
\hline Total & 69 & $(100)$ & 38 & $(100)$ & 85 & $(100)$ & 13.3 \\
\hline
\end{tabular}

T6 Sixth thoracic spinal cord segment. * $P<0.001$ by Fisher's exact test. ICP Intermittent catheterization procedure

$\left(\mathrm{P}=0.4\right.$ by $\chi^{2}$ for trend). Site and severity of spinal lesions had a major impact on the overall infection rate, varying from $73 \%$ of patients with complete lesions at or above the sixth spinal cord segment (T6), to $33 \%$ of those below T6 with incomplete lesions (Table 1).

Clinical signs and symptoms were infrequent (Table 2). Over one-half of infected patients were asymptomatic, and $75 \%$ had no clinical signs of infection. Fever was the most common sign (22.4\%). Urinalysis was abnormal in 51 of the 70 patients in whom it was obtained (50 with pyuria and eight with hematuria). Fifty-six per cent of patients with abnormal and 26\% with normal urinalysis had clinical signs or symptoms of infection. In only three cases was bacteremia documented (3.5\%); blood cultures were not taken in every case. 
TABLE 2

Patient signs and symptoms of infection

\begin{tabular}{lrc}
\hline & Number & Percentage \\
\hline Symptoms & & \\
Incontinence & 3 of 85 & 3.5 \\
Bladder spasms & 4 of 85 & 4.7 \\
Nausea/vomiting & 7 of 85 & 8.2 \\
Chills/rigors & 10 of 85 & 11.8 \\
Asymptomatic & 48 of 85 & 56.5 \\
Signs & & \\
Increased residual urine & 1 of 85 & 1.2 \\
Flank tenderness & 1 of 85 & 1.2 \\
Abdominal distension & 1 of 85 & 1.2 \\
Fever & 19 of 85 & 22.2 \\
No clinical signs & 64 of 85 & 75.2 \\
Pyuria ( $>5$ cells/hpf) & 50 of 70 & 72.9 \\
Hematuria ( $>5$ cells/hpf) & 8 of 70 & 11.4 \\
\hline
\end{tabular}

hpof High power field

Infecting organisms were widely distributed among Gram-negative species: Klebsiella species (38.8\%), Escherichia coli (18.4\%), Enterobacter species (16.5\%). Proteus species (11.6\%) and Pseudomonas aeruginosa (7.8\%). Serratia marcescens and Morganella morganii accounted for $0.9 \%$ each of infecting organisms. Grampositive organisms including Enterococcus faecalis, coagulase negative staphylococci and Staphylococcus aureus accounted for $10.7 \%$ of infecting organisms. No clustering of cases was noted. There was no death related to infection. Despite the relative lack of severity of infections, heavy antibiotic use resulted. A total of 861 days of therapy were given either for acute infection (623 days) or relapse (238 days). One patient underwent prostatectomy for prostatitis and recurrent UTI. Infected patients spent an average of 148 days in hospital (range 50 to 405), whereas noninfected patients spent an average of 25 days in hospital (range 20 to 93), probably also reflecting the severity of the underlying cord lesion.

\section{DISCUSSION}

The primary goal of this project, to demonstrate a reduction of UTIs by reporting infection rates on a monthly basis to the ward staff involved in catheterization combined with educational programs emphasizing aseptic catheterization techniques and the importance of handwashing, was unsuccessful. Since the authors did not actually study the staff's catheterization technique before and after the study was instituted, it is possible that there was no improvement in performance, resulting in no change in UTI rates. It is also possible that the study design contributed to this failure. The retrospective study may have underestimated the true infection rate. Since many infections are asymptomatic, if urine specimens were less frequently submitted for culture, fewer infections would have been detected. The ward policy of submitting urine for cul- ture remained unchanged throughout the study period; however, the authors' presence may have induced more frequent submission of specimens in asymptomatic patients. A more rigorous approach would have been to conduct an entirely prospective study, but to withhold reporting the data for an initial period. It seems unlikely that extending the study would have changed the results, since there was no statistically significant downward trend in month-by-month infection rates. In any case, given the low short term morbidity of these infections, a labour-intensive infection control program may not be justifiable on these grounds alone.

One implication of this failure to reduce infection rates may be that compliance with recommended catheterization technique was good and that with this technique there is an irreducible, minimum number of infections which will occur. Certainly, the overall infection rate of 13.3 per 1000 patient days is very close to that seen by Rhane and Perkosh (1) (10.3 per 1000 patient days), in which prophylactic neomycin-polymyxin irrigant was also used, and lower than another study in which a rate of 19 per 1000 patient days with prophylactic antibiotics, and 65 per 1000 patient days without prophylactic antibiotics, was found (4). Rather than being carried on the hands of the operators, organisms introduced into the bladder during endemic infections may derive from urethral and para-urethral flora (8). Brief disinfection with chlorhexidine may be inadequate to eliminate these organisms prior to passing a catheter.

As in other studies (9), the authors found that most UTIs in this setting are asymptomatic, and that little morbidity results. Only one patient required prostatic surgery for recurrent UTI. Antibiotic use was heavy. however, adding significantly to hospitalization costs. Heavy antibiotic use may account for the greater number of antibiotic-resistant organisms isolated, particularly Klebsiella and Enterobacter species, than reported from a large multi-institutional series of nosocomial UTIs, which found $E$ coli $(32 \%)$ and enterococci (14\%) to be predominant pathogens (10).

In summary, while having failed to demonstrate the effectiveness of a program of regular reporting of infection rates for the purpose of reducing those rates, the authors have confirmed that intermittent catheterization is safe, and that most infection will be seen in a subgroup of severely injured patients in whom recurrent infections, heavy antibiotic use and long hospitalization can be anticipated.

\section{REFERENCES}

1. Rhane FS, Perkosh I. Urinary tract infections occurring in recent spinal cord injury patients on intermittent catheterization. J Urol 1979;122:669-73.

2. Krebs M, Halvorsen RB, Rishman IJ, Santos-Mendoza N. Prevention of urinary tract infection during intermittent catheterization. J Urol 1984;131:82-5.

3. Kuhleneier KV, Stover SL, Lloyd LK. Prophylactic 
antibacterial therapy for preventing urinary tract infection in spinal cord injury patients. J Urol 1985; 134:514-7.

4. Maynard FM, Diokno AC. Urinary infection and complications during clean intermittent catheterization following spinal cord injury. J Urol 1984;132:943-6.

5. Cruse PJE, Foord R. The epidemiology of wound infection. Surg Clin North Am 1980;60:27-39.

6. Timby BK, Lillis C, Grose LG. Clinical Nursing Procedures. Philadelphia: JB Lippincott Co, 1989:474-502.

7. Garner JS, Jarvis WR, Emori TG, Horan TC, Hughes JM.
CDC definitions for nosocomial infections. Am J Infect Control 1988; 16:128-40.

8. Moloney PJ, Doyle AA, Robinson BL, Fenster H, McLaughlin MG. Pathogenesis of urinary infection in patients with acute spinal cord injury on intermittent catheterization. J Urol 1981;125:672-3.

9. Anderson RU, Hsieh-Ma ST. Association of bacteriuria and pyuria during intermittent catheterization after spinal cord injury. J Urol 1983;130:299-301.

10. Haley RW, Culver DH, White JW, Morgan WM, Emori TG. The nationwide nosocomial infection rate. Am J Epidemiol 1985;121:159-67. 


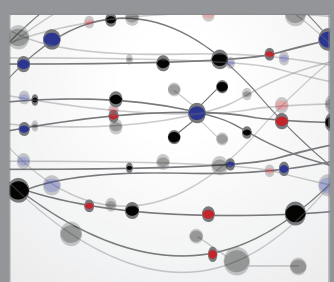

The Scientific World Journal
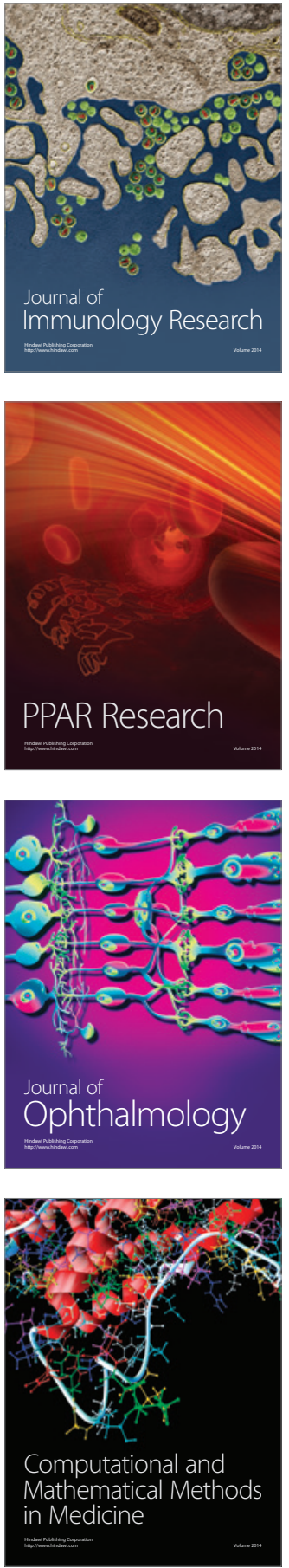

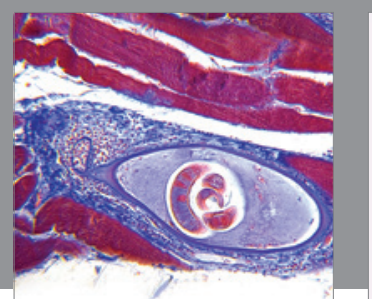

Gastroenterology Research and Practice

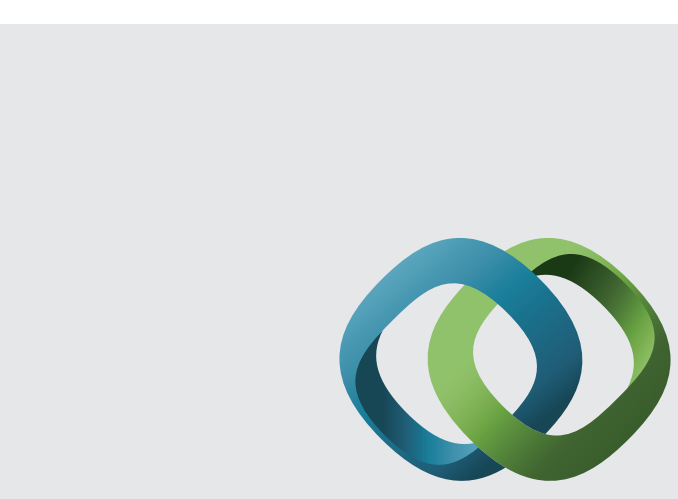

\section{Hindawi}

Submit your manuscripts at

http://www.hindawi.com
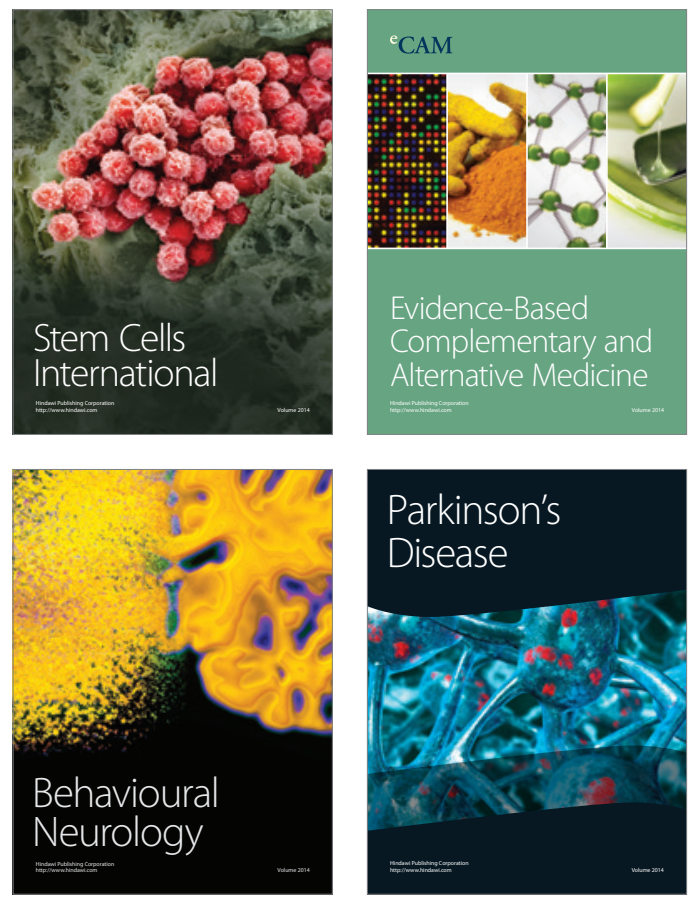
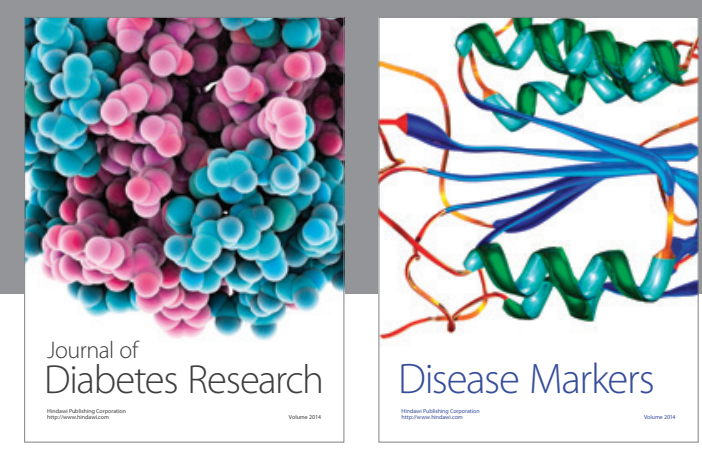

Disease Markers
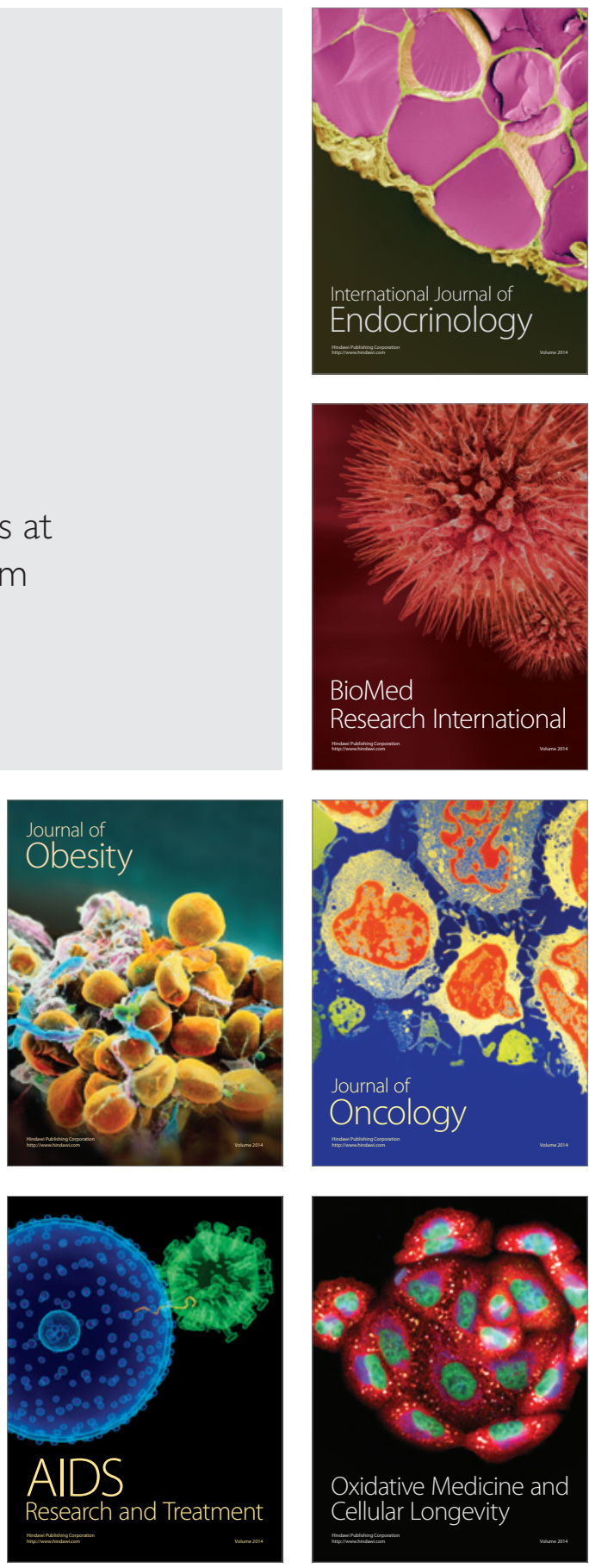